\title{
Behavior science led technology for financial wellness
}

\author{
Jayasree Raveendran ${ }^{1} \cdot J_{0 h n} \operatorname{Soren}^{1} \cdot$ V. Ramanathan ${ }^{1} \cdot$ R. Sudharshan ${ }^{1}$. \\ Suman Mahalanabis $^{1}$ - A. K. Suresh ${ }^{1}$ - Vivek Balaraman ${ }^{1}$
}

Received: 24 May 2021 / Accepted: 21 July 2021/Published online: 2 August 2021

(C) CSI Publications 2021

\begin{abstract}
Financial wellness is regarded as a significant constituent of the overall well-being of individuals. Financial wellbeing is defined as having financial security and freedom of choice, in the present and in the future. This has a direct correlation to overall wellbeing: including productivity experienced at work, quality of relationship, quality of health and hence quality of life. Financial wellness is also challenging as everyone desires to achieve a state of wellness while the pathways to its achievement are not straightforward and can be easily overwhelming to many. In the Indian context, recent reports point to the fact that financial wellness emerges as a top stressor for a majority of people which has also heightened due to the pandemic. A lack of financial wellness thus emerges as a major problem in the country. The prevalence of concerns on financial wellness in fact, is witnessed across the globe. An approach to ameliorating this is through the field of behavioral finance which has uncovered many behavioral
\end{abstract}

Jayasree Raveendran

jayasree.raveendran@tcs.com

John Soren

john.soren@tcs.com

V. Ramanathan

v.ram@tcs.com

R. Sudharshan

r.sudharshan@tcs.com

Suman Mahalanabis

suman.m@tcs.com

A. K. Suresh

ak.suresh@tcs.com

Vivek Balaraman

vivek.balaraman@tcs.com

1 Tata Consultancy Services Ltd., Chennai, India biases and barriers which impact how financial decisions are taken. Examples include lack of awareness of financial needs or awareness of the right products, lack of selfcontrol, confusion in making financial choices or being unable to save/invest at the right time. To address this, we present a holistic and hyper-personalized approach that combines technology and behavioral science to influence financial behavior. The solution aims at enhancing financial wellness of individuals using behavioral levers and nudges. This combines two aspects: (1) an engaging user interface at the front-end and (2) a customer insights/behavioral analytics and intervention recommendation system at the back end that suggests appropriate hyper-personalized actionable steps to the user. The solution helps users to visualize their financial needs, set financial goals and receive appropriate personalized nudges to help them in implementing financial plans as they go through various phases of career/life stages. We present our thoughts on how financial wellness can be extended to address financial inclusion in India.

Keywords Financial wellness - Behavioral influencers · Behavioral analytics technology

\section{Introduction}

Financial wellness is a state that individuals generally aspire for and the consensus among researchers is that personal financial wellness is a sub-construct of overall well-being [1]. The Consumer Financial Protection Bureau defines individual financial well-being as having financial security and financial freedom of choice, in the present and in the future [2]. Personal financial wellness in itself is a comprehensive, multidimensional concept incorporating 
financial satisfaction, objective status of financial situation, financial attitudes, and behavior that cannot be assessed through one measure [3]. Financial wellbeing has a direct correlation to overall wellbeing: including productivity experienced at work, quality of relationship, quality of health and hence quality of life. [4]. Lack of financial wellness has been linked to behaviors that affect the quality of people's lives. According to [5], close to 1 in 5 Americans considered skipping or actually skipped a medical appointment because of financial worries-even though they needed healthcare. At the root of a lot of people's financial discomfort and stress is their emotional relationship to money and financial decisions [6], where worries about retirement, debt, and the strain of living paycheck to paycheck were identified as common stressors. Other money worries include job insecurity, investment performance, and low credit scores. In India, the RBI committee on household finance showed that only 5\% of the average Indian household's wealth is in financial assets, which is very different from the pattern in the developed economies, where the proportion of financial assets is much higher. The report points out Indian households are exceptional, as India is the only country in which mortgages account for an increasing share of total liabilities as people approach retirement age, leaving them exposed to repayment risk even in old age [7]. Thus, concerns in financial wellness is seen to be a persistent issue globally.

The heightened need for financial wellness and a realization that there must be a concerted system-wide effort to enhance financial wellness of individuals has come out clearly in the wake of COVID-19 pandemic. During this pandemic, many lost their livelihood and became more vulnerable to face challenges in life. According to a study by McKinsey in 2020, between 20 and 60 percent of household decision makers say they fear for their jobs in most countries, and such people across the globe have reported decreases in income and savings ranging from 30 to $80 \%$ [8].

Leaving the pandemic impact aside, an intriguing question that still remains is: while everyone would aspire for financial wellness, why is it that over time and across the globe, most individuals have not been successful in 'focusing' on being financially prepared to meet their respective needs and goals? A potential convincing response comes from the field of behavioral finance. As [9] puts, "Behavioral finance substitutes normal people for the rational people in standard finance". The standard approach to predicting human behavior suggests that, as rational human beings, we consider all available information, weigh the pros and cons of each option, make the best choice, and then act on it. The behavioral approach shows us something different. We make decisions with imperfect information and do not always choose what is best for us.
Behavioral science has been used across a variety of fields to realign policies, programs, and products with how we really behave, improving outcomes for millions of people worldwide [10]. Using a behavioral science led approach, fused with technology can potentially enable financial inclusion at scale.In this paper, we focus on a behavioral technology-based solution that can be personalized to the user to enable creation or addition of financial goals, identify behavioral patterns of the user to provide them with insights on their proximity to goal achievement and also help them with actionable steps that users could take to achieve the stated goals. The solution conceived focuses on a holistic engagement with users along their life/career paths, empathize with individuals to create realistic financial goals that match their financial persona and empower individuals with interventions that result in habit formation and thus help them take behaviorally aware decisions for financial wellness. The next section discusses behavioral influences in the context of financial wellness and Sect. 3 discusses possible angles of attack to address issues in financial wellness. Section 4 presents details on the solution approach and the components thereof. Section 5 presents possible angle of attacks to address behavioral bottlenecks in financial inclusion and Sect. 6 presents the discussion and conclusion.

\section{Review of literature}

A recent $\mathrm{PwC}$ report of 2021 highlights that most younger employees in the U.S.A. are experiencing increased financial stress due to the pandemic and that employees are looking for a wider range of options to address their own financial situations, from student loan paydown plans to retirement options [11]. In response to the economic impact of COVID-19, Australians are mostly reducing their spending and there appears to be a high level of caution with spending, even among those whose income has not changed [12]. In India, households' financial savings rate dropped to $10.4 \%$ of the GDP in the July-September 2020 quarter compared with $21 \%$ in the preceding quarter, as per the central bank's preliminary estimates on household savings [13]. As India is going through the second wave of the pandemic, unemployment touched $8.6 \%$ for the week ending April 11, 2021 from 6.7\% during the end of March, 2021, as per data by the Centre for Monitoring Indian Economy Pvt. Ltd. [14]. The picture given here seems to be a world-wide phenomenon and hence calls for an approach that is innovative, empathetic, and scalable to address issues in financial management of individuals. It may also be noted that financial wellness concerns have existed in general even before the COVID-19 and the behavioural approach to financial wellness might be different during the 
COVID time compared to normal times. However, with the wealth of evidence we see from behavioral science literature on why people are not able to take financial decisions that are best for them, it would be pertinent to integrate behavioral science with technology based solutions for addressing issues in financial wellness at large.

\subsection{Behavioral influences in financial decisions for wellness}

A prominent reason for why individuals do not act in their best interest in planning for financial wellness is attributed to a lack of financial literacy [15]. Financial Literacy encompasses possession of a few latent skills and knowledge to help make informed decisions and work towards Financial Well Being. It includes aspects of knowledge, attitude and behaviour covering the range of context such as money management, planning for short- and long-term financial goals and awareness and choice of financial products. Financial literacy can be interpreted as the level of understanding of the topic of money. Higher literacy is deemed to improve confidence, sentiment, financial knowledge that enable an individual to take better financial decisions. However, there could be behavioral biases and barriers that may come in the way of financial planning. For example, a lack of self-control may lead to the inability to save for the future [16]. Consumers can also have inertia or a short-term focus which prevents them from thinking about the future [17]. Loss aversion or risk aversion can also be factors that can come in the way of implementing financial plans [18]. For example, the COVID-19 health crisis seems to have disproportionately affected baby boomers, where investors over 65 years sold equities early on amid the pandemic as loss aversion played a role in their investment decisions [19].

An important determinant of intertemporal choice is a person's sense of psychological connection with his or her future self $[20,21]$. Absence of psychological connectedness between a person's current self and future self also prevents people from saving for their future. Termed as present bias, the root of this bias is the manner in which time alters our perceptions. When we think about the distant future, our mental representations are often abstract and vague, whereas our mental representations of the near future are concrete and vivid. Thus, there might be a tendency to avoid the task of planning for the future which is vague at the moment. On the other hand, we may also avoid planning for the future because we're overconfident-that is, we believe that we'll be able to achieve our goals regardless of the obstacles. As [10] highlight, overconfidence is endemic among us: most of us think we have better than average driving habits, that we eat less red meat than others, and that our business ventures are more likely to succeed. We can justify our lack of retirement preparation by convincing ourselves that things will just work out in our favor, or that we'll be able to cope with any situation that arises.

Planning for financial wellness could also be negatively affected due the problem of information overload whereby individuals feel there is too much information, and this makes it more difficult to make retirement decisions. Some further concrete reasons why people don't save enough for the future are that people don't have enough money or income [22], have other goals, think they have more time, thought their job was a short gig so they don't invest in a retirement plan, or don't believe it is important and necessary [23] or even simple procrastination [24]. For millennials, key reasons include a focus on student debt, or employers don't offer retirement plan, or a perception that they don't have enough money and therefore consciously decide not to save [25]. There are, of course, also a number of external factors such as religion [26], culture [27], access to financial advice, [28] financial system development [29],demographics and economic environment that could influence financial decisions of individuals and differences in decisions patterns thereof have been documented in literature.

\subsection{Behavioral interventions for financial wellness}

Analysis of individuals' behavior is becoming increasingly important for financial service providers to understand how financial wellness issues can be addressed. The idea to use insights gained from observing financial behaviors to provide them with actionable recommendations based in a real understanding of their economic position. Use of insights from behavioral finance and behavioral economics is garnering attention in influencing behavior in not just shortterm outcomes, but in the long term as well. There can be a number of ways where decision making could be guided. Eliminating the issue of presenting too much information at a time, also known as cognitive overload, is one tried and tested approach. With the use of cognitive science, BBVA's mortgage group in Spain took on the task of simplifying language and providing easy-to-use calculators in its online mortgage and loan applications. By using more consumer-friendly language, the group was able to realize an increase in completed applications of more than $150 \%$ [30].

Recent research also finds that emotional appeals can often be more effective or powerful [32]. There is evidence that emotional appeals require less concentration and effort than other types of messages and are easier to process. They are also more vivid and easy to remember, are more interesting, generate less resistance, and more directly lead to action. In addition, it has been found that concrete 
emotional appeals are more effective in stimulating shortterm behavioral intentions [33]. This would suggest that if the goal is to instigate savings for the future in the short run, concrete emotional messages would be beneficial. A range of behavioral interventions for financial wellness is accumulating in research that uses choice architecture, commitment features, incentives and client communication mechanisms [34].

Recently, researchers have begun to explore the enormous potential of 'digital nudging'. For instance, [31] outlines three new case studies that show how the improvement of the design of the online world can have a big impact on participants' financial behaviors: (i) an email intervention on enrolment in a savings program nearly doubles the program enrolment; (ii) robo-saving apps directly and promptly encourage people to save more; and (iii) a personal capital mobile app (offering an account aggregation service that brings together all of a consumer's financial accounts) helps people to decrease their monthly spending by 15.7 percent. Customers are more likely to develop and stick to a savings strategy if banks are able to collect data about their financial position and then show them how they compare with similarly situated peers. However, digital solutions that use nudges should be carefully designed, must be trustworthy and should ensure that the nudge is ethical and is directing users to make choices in their best interest. There also exists a fine line between digital nudging and spamming or phishing attacks. Users hence should be reassured of safety and trust by service providers while users would also need to be aware and be cautious not to fall a prey to such attacks.Possible angles of attack to address behavioral bottlenecks in financial wellness.

\section{Possible angles of attack to address behavioral bottlenecks in financial wellness}

Possible angles of attack on the problem could include using the following inputs by financial service providers to understand, engage with and positively influence the decision-maker towards better choices for financial wellness:

\subsection{Effective engagement with the user}

The need to empathetically engage with the user as well as sustain the engagement is crucial to get people onboarded and set them on a path towards planning for financial wellness. Enrolling customers for a new product or offering is the first hurdle to clear when improving access and use of financial services. Financial service providers face many challenges in getting users to sign up, retaining, and activating the customers they seek to serve. Towards this, focusing on design elements that are easy to use, intuitive and those that enable actionable steps that users can easily take would be important to create [35]. For example, an interface that builds a connect say with a chatbot, which guides the user to set financial goals, connect with an advisor as needed and gives informational nudges or prompts the user to take relevant next in a timely manner are certain elements that technology and design can create to give a meaningful and interesting experience to the user. There can also be different engagement and communication approaches that can help users suffering from emotional influences such as loss aversion. To identify and potentially treat a bias behavior, financial service providers, through advisors, could establish objective rules towards financial planning and investment decisions and provide more realistic viewpoints to help users better balance their understanding of an investment opportunity [19].

\subsection{Personalizing the solution}

Financial service providers could consider using visualization exercises and goal-setting activities, including labeled accounts, personalized reminders and regular feedback in the solutions. Making solutions hyper-personalized with the intelligence in the system to engage with the user across life stages or financial decision stages could be a strategy [10].

\subsubsection{Understanding career/life stage}

Consideration of significant life events such as entering into education, starting a career, marriage/divorce, family expansion, addressing health needs, retirement etc. are significant events for which individuals have to be financially prepared for. Enabling this preparedness through life stage / career stage specific nudges or interventions.

\subsubsection{Understanding financial decision stage}

Financial decisions typically have the following stages: Need realization, information search, goal setting, implementation of goal related activities, goal monitoring and goal achievement/enhancement. This is a fairly iterative and a non-linear process as people move up a stage or regress into an earlier stage. There could also be barriers in decision making in the various phases such as decision inertia, dilemmas, procrastination, present bias, self-control issues etc. Interventions to counter specific biases/barriers in various stages of decisioning can be delivered at appropriate points (Fig. 1).

The above figure depicts the various stages involved in making financial decisions. Devising interventions to be 


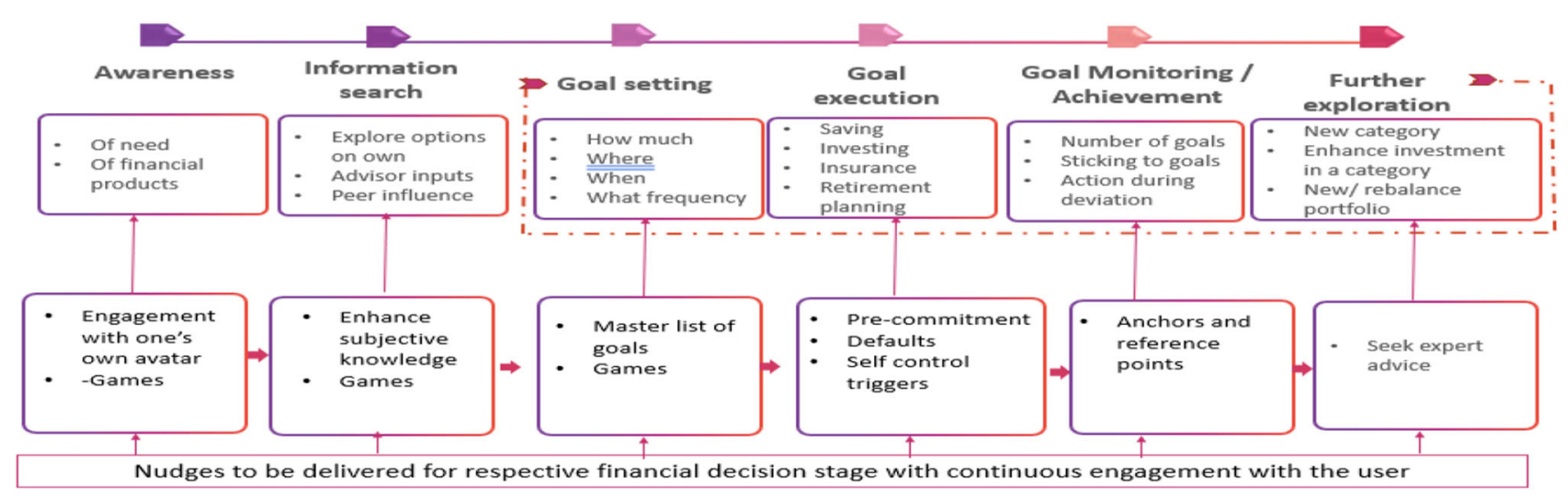

Fig. 1 Stages in Financial decision making and sample nudges to be delivered at respective stage

delivered to the user at every stage to nudge the user to take the next step in accordance with the plan could be an effective way to enhance user engagement and to help in any course correction as the user traverses the path to achieve financial goals. At every decision stage, the kinds of relevant nudges that could be delivered to the user are also indicated, which the user could be received at appropriate points along the journey towards financial goals.

\subsubsection{Curating behavioral interventions for advancing in the financial goal trajectory}

Behavioral finance literature can be curated to identify specific interventions that can be personalized to match the persona of the user/match the user's life/career stage or the course of the decision journey. By engaging with users to help them take important behavioural steps towards the financial goal, financial institutions can increase the likelihood that their customers will meet their financial goals. For example, customers can be encouraged to specify implementation intentions by explicitly planning the steps towards their financial goals, such as when they will transfer income to savings, where they will do it (e.g. at home or work), and how they will do it (e.g. online or at the bank).

The solutions from financial service providers could be personalized to facilitate the use of defaults, where savings are automatically deducted from income. The solution can also suggest escalation of future commitments. which frame the choice between two future selves rather than heavily favoring the present self or allowing individuals to make their own binding commitments by setting their own restrictions on their access to their money [34]. Technology also allows for different interventions and different bundles of interventions to be delivered to different customers and for the collection of inexpensive real-time data on the behavioural responses to these interventions. These data should be analyzed to establish which approaches are working, and to incrementally test new versions of the interventions to find the most effective strategies to encourage savings behaviors [36].

\section{Solution approach and components}

In the backdrop of the above discussion, we present our approach for addressing financial wellness at scale, using behavioral science led technology. The solution combines two aspects: (1) an engaging user interface at the front-end and (2) a data driven customer insight / behavioral analytics-and-intervention-recommendation-system at the back end that suggests appropriate hyper-personalized actionable steps to the user. The solution helps users to visualize their financial needs, set financial goals and receive appropriate personalized nudges to help them in implementing financial plans as they go through various phases of career /life stages.

The enterprise data security and protecting the customer data is the foremost consideration while building the solution. The solution modules are designed in such a way to gather the vital information that is required to understand the current state of customer's financial wellbeing. The data collection process is automated and stored securely within the enterprise database system. The service provider would get intelligent insights from the data for better customer understanding and for devising a personalized engagement program. The application and the database access are strictly controlled by the authorization protocol and the audit log tracks the database access.

\subsection{Front-end interface as a planning tool}

An individual's savings or investments could be focused to accomplish a predetermined goal (s) or just used to realize the on-demand need. Individuals typically save in unplanned manner and deposit their savings in various 
financial instruments. Most Indians have a saving focus that is predominantly focused on bank deposits [7]. While saving money is important, investment in the right instrument and at the right time is equally important to grow one's wealth. To realize the objective of gaining financial security, a disciplined and methodical savings approach is required in terms of goal creation and management. The concept of goal-based financial planning is assuming significance thanks to the continuous awareness campaigns by the wealth management companies, FinTech companies, and financial companies. The goal-based planning is a systematic way to identify the goal, understand its relevance to the current and future financial situation, and to create an investment plan, either periodical investments or a lumpsum for a defined period. The goal period could be short, medium, or long-term. An action plan, that is achievable, genuine, and practical is very significant in the financial planning journey. The objective of the goal-based planning is to either help the individuals to increase their savings or reduce the expenses/debts, which could be recycled towards a new financial instrument. Banking and insurance companies have their own financial planners to help customers to perform what-if financial analysis. In addition to having a financial planning tool, it is imperative to offer a goal-based planning tool that could help customers to perform an end-to-end goal planning activity.

An ideal goal-based planning tool is one that would reimagine the current financial planning exercise. It should incorporate the principles of:

- Inculcating a sense of financial inclusivity among family, friends, advisors, and communities

- Enabling the users to share and gain financial knowledge from the connected stakeholders so that relevant goals can be set, managed, and achieved.

- Providing the personalized goals instead of listing the end financial product. The goals could be eventually mapped to the product (s)

- Connecting and sharing real-time experience within the user community

- Nudging the users to improve their financial behavior

- Creating a personalized offering such as suggesting new goals/promotions/awareness campaigns etc.

- Providing a dynamic dashboard and a timeline view on the status of the goals achieved and the opportunities missed

- Enabling the users to create and manage content. The personalized financial goal planning content could also be pushed to the user for future action

The front-end planning tool comes with the above features to engage with the users to enable them set goals and navigate through the goal journey. A well-designed financial planning tool is critical for both the users and the service providers. For users, it is the tool that supports them to capture their financial needs and aspirations and help them to realize the life's objectives. For service providers, it is the gateway that connects the users to the company and helps them to get 360-degree customer view thereby extending service beyond the core needs. Hence designing the front-end in an engaging way is of paramount importance to the companies. The solution front-end has been designed to provide a superior customer experience to the users. The solution displays personalized contents considering the current life stages and the user needs and interest. The elements of nudge theories are followed in designing the layout and the contents. The solution has elements of welcoming the user with right information, promising the users that transaction/ activities would be fulfilled to the user satisfaction, protecting the user from different attacks, connecting with the user and providing the relevant and contextual information and functionalities, and finally taking the responsibility for any inadvertent error and resolving them to the satisfaction of the users. To cite an instance of the better design practice in the solution, the fact-finding screen is designed in a way to gather information about investment risk appetite, personality, emotionalitys and so on. These data help the providers to understand the customer's financial and emotional wellness. Summing up the innovative initiates includes responsive web design, unlimited scroll layout, widgets, collaborative features, multimedia content, single portal for customer's and their connections, ecosystem driven advice and so on (Fig. 2).

\subsection{Customer insights system}

The Customer Intelligence \& Insights (CI\&I) system establishes a common foundation for enriched customer understanding enabling banks to build long term customerbank relationships through empathetic engagements. The system synthesizes data from both enterprise systems like transaction data from payments, cards, deposits, checking and savings accounts, investment portfolios, interaction data from call centers, digital clickstream, call notes or any outbound communication and external data sources like credit bureau scores, transaction aggregators, social brand interactions and macroeconomic open data and applies AI and machine learning techniques to create individual customer personas, infer behavioral preferences and recommend personalized empathetic engagements. A key element of such data processing is its in-built support for data privacy and consent check from each individual customer.

CI\&I system helps in providing a consolidated view of customer across various product holdings of the financial service provider and also helps determine the 


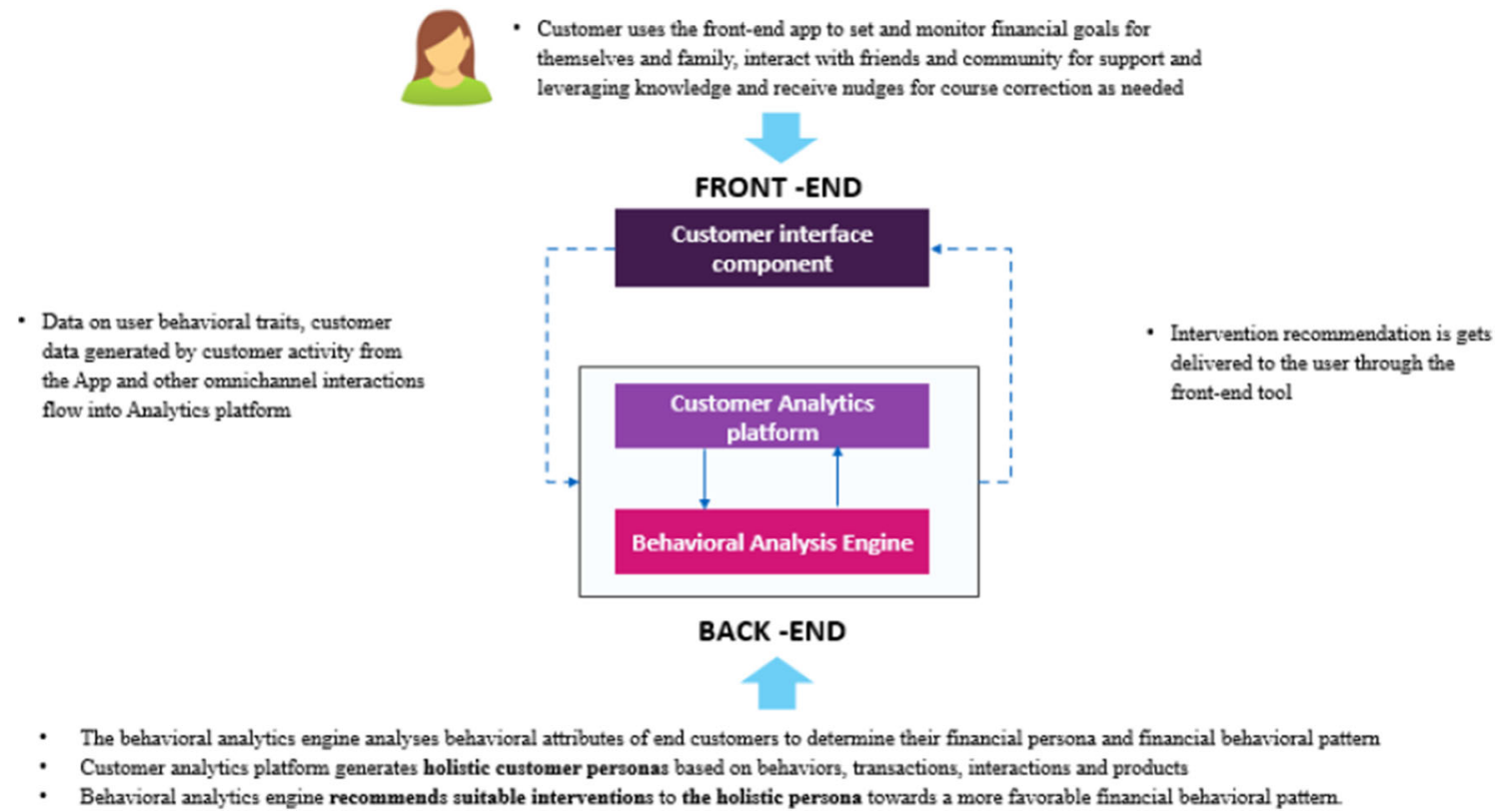

Fig. 2 Financial Wellness Solution components

characteristics of customers based on their behavioral attributes. The system enables determination of digital personas based on demographic and lifestyle data. This system has behavior models that segments customers based on the digital persona, value, demographic and digital persona. The propensity models in the system determine customers inclination or likelihood to conduct themselves about choosing a channel or a product. Based on the learning of individual customer personas, preferences and portfolio holdings, customer insights provide contextual engagement recommendations. Such recommendations can either be for the Next Best Action or for Next Best Offer that can be proposed given the context of the individual customer, context of the interaction and also in context of their behavioral personas. This is enabled by CI\&I system through a range of unsupervised and supervised machine learning techniques to deliver empathetic engagements. For example, behavior clustering and look-alike modeling for discovering personas and creating cohorts based on behavioral, transaction and psychographic profiles. NLP algorithms and topic modeling techniques are applied to discover key sentiments and topic of interests for individual financial users that feed into affinity and event driven NBA models to generate empathetic nudges and next best action. Additional AI models for speech and emotion detection helps in enriching empathetic response at the point of engagement in live interactions with the financial institute's call center, relationship managers and digital advisors. A decision modeling environment within CI\&I provides business users with an ability to fuse such AI and ML techniques along with business rules to orchestrate empathetic nudges and next best action responses across digital and physical channels. In addition it provides support for Responsible AI through interpretability and bias avoidance for the continued governance of AI enabled empathetic engagements towards financial wellness.

\subsection{Behavioral analytics engine}

Every behavior change process requires a system to understand the existing state, understand patterns in behavior and then recommend interventions as needed. These capabilities are built in the other back-end component in the solution is the behavioral analytics engine, which does behavioral data capture, pattern analysis, and recommends interventions that are to be delivered to the user. The engine is capable of capturing multi-modal behavioral data through voice, image, video, or text. Using this engine, individual insights can be generated based on goals set and the individual's stage in the goal achievement trajectory. The platform allows people to register with it using pseudo-identities and avoids collecting any personally identifiable data. Data that is gathered is also managed in compliance to the regulations, such as the GDPR, giving people full control over their data. The GDPR features such as ability to get a copy of all personal data by the user, withdraw from the data collection, delete all data from the system etc. are made accessible through the platform. [37]

Various patterns of activities performed can be discovered through the pattern recognition algorithms. A pattern could be: lack of activity, pattern of expenditures, pattern in savings, patterns of risky behaviors etc. The engine has a 
repository of interventions obtained from research literature in the space of financial decision making. Such interventions can be mapped to a behavioral persona (obtained from behavioral surveys and combined with the behavioral patterns identified by the system) and an intervention can be recommended. The engine consists of various modules that enable pattern discovery, intervention recommendation, and behavior simulator to compose behavioral models in understanding dynamics of a situation to predict future behaviors). The Behavior Knowledge base in the engine comprises of behavioral insights mined from behavioral finance literature. It also contains evidence for interventions that have been validated in the field. The behavioral knowledge base is enabled by a knowledge mining infrastructure that has various classifiers and information extractors to mine the target knowledge fragments into the repository. [38].

\subsection{How the solution elements come together for financial wellness}

In this section, we explain how the solution is operationalized. The user uses the front-end app to set and monitor financial goals for themselves and their family, interact with friends and an online community for support and to leverage financial knowledge.

Once goals have been set and the system is 'activated', the user will receive personalized alerts, reminders, other nudges for planning and feedback of activities that aid in goal achievement for the user. At the back end, data on user behavioral traits, customer data generated by customer activity from the App and other omni channel interactions flow into the Customer Insights (CI) system. The customer analytics system may invoke the pattern recognition algorithm in the behavior analytics engine in order to detect user patterns and the persona. The engine analyses behavioral attributes of end customers to determine their behavioural pattern. It recommends suitable interventions to bring about a more favorable financial behavioral pattern. These interventions are passed onto Customer-facing digital channels which the user absorbs and may act upon. The CI system maintains investor life events, and passes on life event and persona to receive intervention recommendation from the behavior analytics engine. CI also tracks if user reacted to the earlier delivered intervention and passes the information to behavior analytics engine to deliver the next appropriate nudge to the user.

We now illustrate as to how this framework can come into action by taking the day in the life of a typical persona from the Indian female populace. We call the hypothetical Financial Advisory system based on the system we are building as Fin Companion just for sake of illustration.
Let us consider Asha, a young female, who is single and who has just got into a career. The lifestyle of this individual is characterized by behavior such as budgeting for necessary category spends like rent, food, clothing, grooming, weekend outings, retail therapy and as a consequence has very little savings. Asha looks for better saving guidance and comes across the Fin Companion system. The Fin Companion elicits various behavioral information from Asha through a gamified survey and conducts behavioral profiling for Asha. From information given by Asha to the questions in Fin Companion, we come to know that Asha is an Intuitive persona whose financial knowledge is low, has low levels of self-control, is risk averse and feels comfortable to have guidance from others on important matters. She needs help with managing her present lifestyle and future financial needs. The behavioral analytics engine then presents nudges that include helping her with embarking her on a financial planning journey, presents a choice of what actions can be taken with easy guided steps and informs her on what peers are doing. In this case, Asha is helped with setting up financial goals that match her persona. Asha further receives nudges that enables her to visualize future financial needs and prepares her to save accordingly. Identifying that information on peer behavior resonates with Asha (based on her behavioral profile), Asha is nudged with information on how and where her peers are saving or investing their finances.

Another example is of Charu, who is in different lifestage, a middle-aged, employed, single parent with a school-going child, Charu, is identified as a Deliberate persona with the following behavioral characteristics: Is aware of her financial needs but needs guidance, is riskneutral, high in self-control and analyzes costs and benefits of while making decisions. FinCompanion helps Charu in setting her financial goals to meet educational expenses of her child and insurance planning for health and property. When she receives a salary hike, FinCompanion will send Charu a nudge to enhance contribution to her retirement plan, so she can be better prepared for a comfortable retirement.

We could take another example from the financially underserved section, Kumar, who runs a small Kirana store. Kumar has his own shop and has taken a loan for his business. Kumar has been thinking of savings for his personal and family needs. Kumar downloads Fin Companion in his smart phone and he is classified as a Realistic persona (Low in financial knowledge, high in self-control, risk-taking and seeks guidance for managing his finances). Kumar could be guided towards setting financial goals for saving in various bank products and to track his expenses on a regular basis to keep them under control. Kumar is then prompted to plan for set next set of goals receives a 
family oriented nudge for insurance and starts to think of insurance plans for him and his family.

FinCompanion also tracks if Asha or Charu or Kumar are responding or not to the nudges, and if not, may deliver the next nudge that matches their respective behavioral profile. There is thus constant engagement with the user with activity monitoring and feedback on behavior and ensuring guidance for behaviorally informed decisions for financial wellbeing, for both the current and future time horizons.

\section{Possible angles of attack to address behavioral bottlenecks in financial inclusion}

At a systemic level, financial inclusion means that individuals and businesses have access to useful and affordable financial products and services that meet their needstransactions, payments, savings, credit, and insurancedelivered in a responsible and sustainable way [39]. Financial inclusion is fundamentally about bringing the unbanked or underbanked into the formal financial system-focusing on customer segments who have traditionally been left out. These segments include women, rural populations, and historically underserved ethnic and religious groups. With the advent of digital platforms and services, digital financial inclusion involves the deployment of the cost-saving digital means to reach currently financially excluded and underserved populations with a range of formal financial services suited to their needs that are responsibly delivered at a cost affordable to customers and sustainable for providers [40].

Today, there is also an increased advocacy in favor of "open data" combined with increased customer control over who those data may be shared with and under which conditions. In the context of banking, open data has translated into "open banking" regulations, empowering customers to authorize banking institutions to share their personal data with third parties for the purpose of obtaining greater access to finance in a more open and competitive market. Here, such account aggregation needs a regulatory set up, such as adherence to the UK's Open Banking Standards or Consumer Data Right (CDR) Act of Australia.

Witnessing the evolution of technology-driven business models that make finance more accessible, inclusive, and competitive through connecting and analyzing data, the concept of open banking is evolving into "open finance". To reach optimal adoption, open finance in turn calls for the continued evolution of new infrastructures, such as individual and corporate digital identity [41].

In the Indian context, the India Digital Financial Inclusion report of 2019 presents findings from research that will help the digital finance space to grow in a more inclusive way. The finding also appears to have behavioral implications and it would be important to consider how the following findings can be addressed to promote inclusive financial wellness.

- Even as technology enables rapid scaling of business models, the need for trust and understanding of how to use these services will continue to require interaction with a human being at the last mile

- Digital finance is closely linked with aspiration-in both urban and rural environments, the desire to try new digital products and continue to use them is closely linked with aspirational characteristics like wanting to grow a business or participate in the broader national digital economy.

- Product design is important and underrated-a number of models appear to have struggled because financial services do not meet the differentiated needs of Indian populations.

- A lot of people still prefer cash-much of the movement towards digitization assumes that it provides an improvement on cash-based payments. This can overlook the complexities around why some people use cash and the difficulty of changing behavior.

- More exploration is required around the linkages between digital payments and financial inclusionwhile great progress has been made the access to financial services, the relatively low levels of usage hints at a disconnect between what is assumed to be the impact of digital financial services and the reality on the ground [42].

It must be emphasised that the problem is not an easy one to resolve globally and for India. However, to address the above, technology enabled behavioral analytics and insights from behavioral sciences can help banks and financial institutions to implement preventative measures to help customers avoid overdrafts, missing payments, or neglecting savings plans and pension contributions. Despite their best intentions, however, financial service providers often struggle to target and enroll customers from these groups. Traditionally, they have focused on marketing campaigns - through SMS, radio, and billboard advertisements - to let people know about new services. But behavioral science suggests some alternative strategies that may be more effective at triggering action. For example, mobile money platforms may not be "top-ofmind" for customers at the moment they are performing certain financial transactions. In such cases, a behaviorally informed SMS message to encourage users transact on the platform or highlighting evidence of what others are doing (called social proof) can increase customer engagement [43]. Banks could also use behavioral insights to understand differentiated needs of Indian population and engage 
with customers at a more personalized level, such as the example of Kumar as a behavioral persona discussed in the earlier section. While such an extent of personalization for financial inclusion might appear to be a long shot, steps towards creating an infrastructure for enhancing digital literacy could be worked on.

\section{Discussion and conclusion}

This paper discusses an approach for addressing the problem of lack of financial wellness by using behavioral science led technological solution that engages with the user throughout life/career stages. Upon creating this engagement with the user, we discuss ways of steering actions of users towards financial wellness through delivering appropriate personalized nudges that match the behavioral attributes of the user. The solution combines two aspects: (1) an engaging user interface at the front-end and (2) a data driven customer insights/ behavioral-analytics-and intervention-recommendation system at the back end that suggests appropriate hyper-personalized actionable steps to the user. The solution helps users to visualize their financial needs, set financial goals and receive appropriate personalized nudges to help them in implementing financial plans as they go through various phases of career /life stages. The key takeaway of the approach pertains to the use of behavioral science insights to understand the user better and influence behavior of the user in an informed, structured and engaging way.

We also present our thoughts on how financial wellness can be extended to address financial inclusion in India. The role of technology enabled behavioral analytics and insights from behavioral sciences for addressing specific issues for financial inclusion in India are discussed. However, a problem that would still persist is to see how such solutions would reach the majority of Indians who may not have a smartphone. Digital literacy is a challenge in India and ways of improving digital financial literacy and creation of necessary infrastructure must be worked upon. As opined by the OECD [44], Digital financial services, when provided in a responsible way within a robust infrastructure, may contribute to increased resilience of the financial sector and of individuals in times of crisis. Integration of the behavioral approach could present the real stakeholders needs in a salient manner and can help in design of right technology enabled interventions in financial services for financial wellness at scale.

\section{References}

1. Joo S (2008) Personal financial wellness. In: Xiao JJ (ed) Handbook of consumer finance research. Springer, New York, NY, pp 21-33

2. CFPB (2015) Financial Well-being: The goal of financial education https://files.consumerfinance.gov/f/201501_cfpb_report_ financial-well-being.pdf

3. Joo S (1998) Personal financial wellness and worker job productivity. Dissertation, Virginia Polytechnic Institute and State University, Blacksburg, VA

4. Alban K (2021) Guest post: the correlation between financial wellness and health https://www.virginpulse.com/blog-post/thecorrelation-between-financial-wellness-and-health/ accessed on May 222021

5. American Psychological Association (2015) Stress in America, paying with our health, stress-report.pdf (apa.org). Accessed 12 May 2021

6. Park JJ, Sela A (2017) Not my type: why affective decision makers are reluctant to make financial decisions. J Consum Res. https://doi.org/10.1093/jcr/ucx122

7. Report of the household finance committee (2017) Indian Household Finance, https://rbidocs.rbi.org.in/rdocs/Publication Report/Pdfs/HFCRA28D0415E2144A009112DD314ECF5C07. PDF accessed on 12 May 2021

8. McKinsey report (2020) Financial life during the COVID-10 pandemic - an update, Financial life during the COVID-19 pandemic-an update I McKinsey accessed on 12 May 2021

9. Statman, M (2019) Behavioral Finance - The second generation. CFA Institute research foundation https://www.cfainstitute.org/-/ media/documents/book/rf-publication/2019/behavioral-financethe-second-generation.ashx accessed on 12 May 2021

10. Fertig A, Lefkowitz J, Fishbane A (2015) Using Behavioral science to increase retirement savings a new look at voluntary pension contributions in Mexico I42_571_MexicoPensionsReport_ENG_final_digital.pdf (ideas42.org) accessed on 12 May 2021

11. PwC (2021) PwC Employee Financial Wellness Survey https:// www.pwc.com/us/en/services/consulting/workforce-of-the-future/ library/employee-financial-wellness-survey.html accessed on 12 May 2021

12. Warren D, Baxter J, Hand K (2021) Families in Australia Survey: life during COVID-19 https://aifs.gov.au/publications/financialwellbeing accessed on 10 May 2021

13. Sen S (2021) https://www.newindianexpress.com/business/2021/ mar/20/pandemic-ate-into-household-savings-ina-big-way-injulyseptember-2020-rbi-2279005.html accessed on 12 May 2021

14. Beniwal V (2021) https://www.business-standard.com/article/ economy-policy/india-sees-job-losses-as-states-impose-lockdownsto-check-new-covid-19-wave-121041200442_1.html accessed on 13 May 2021

15. Lusardi A, Mitchell, OS (2010) How ordinary consumers make complex economic decisions: financial literacy and retirement readiness. CF Working Paper No. 2010/11. Goethe University, Center for Financial Studies (CFS), Frankfurt

16. Laibson DI, Repetto A, Tobacman J, Hall RE, Gale WG, Akerlof GA (1998) Self-control and saving for retirement. Brook Pap Econ Act 1:91-196

17. Wayne DH, Krohmer H (2020) The retirement planning crisis: finding a way out with a consumer behavior perspective. Rev Market Res 17:77-85

18. Benartzi S, Thaler R (2007) Behavioral economics and the retirement savings crisis. Science 339:1152-1153

19. Aguilar $O$ (2020) Loss aversion and confirmation bias: emotion in motion https://www.schwabassetmanagement.com/content/loss- 
aversion-and-confirmation-bias-emotion-motion accessed on 22 May 2021

20. Schelling T (1984) Self-command in practice, policy, and in a theory of rational choice. Am Econ Rev 74(2):1-11

21. Thaler R, Shefrin H (1981) An economic theory of self-control. J Polit Econ 89(2):392-406

22. Lusardi A, Keller PA, Keller AM (2008) New ways to make people save: a social marketing approach. In A.Lusardi (Ed.), Overcoming the saving slump: how to increase the effectiveness of financial education and saving programs. Chicago, IL: University of Chicago Press

23. Schroeder-Gardner M (2017) https://www.makingsenseofcents. com/2017/04/saving-for-retirement.html accessed on May 13 2021

24. Gamst-Klaussen T, Steel P, Svartdal F (2019) Procrastination and personal finances: exploring the roles of planning and financial self-efficacy. Front Psychol. https://doi.org/10.3389/fpsyg.2019. 00775

25. Lobosco K (2018) $66 \%$ of millennial's have nothing save for retirement. CNN Money https://money.cnn.com/2018/03/07/ retirement/millennial-retirement-savings/index.html\#: $\sim$ text= About\%2066\%25\%20of\%20people\%20between,National\%20 Institute\%20on\%20Retirement\%20Security. Accessed on 13 May 2021

26. Renneboog L, Spaenjers C (2011) Religion, economic attitudes, and household finance. Oxf Econ Pap 64(1):103-127. https://doi. org/10.1093/oep/gpr025

27. Breuer W, Quinten B (2009) Cultural finance. SSRN: http://ssrn. com/abstract $=1282068$

28. Collins JM (2012) Financial advice : A substitute for financial literacy ? Fin Serv Rev 21:307-322

29. Kwok CCY, Tadesse S (2006) National culture and financial systems. J Int Bus Stud 37(2):227-247. https://doi.org/10.1057/ palgrave.jibs.8400188

30. Moore L (2019) BBVA uses Behavioral Economics to guide consumer decision-making https://www.bbva.com/en/bbva-usesbehavioral-economics-to-guide-consumer-decision-making/ Accessed on May 132021

31. Benartzi S (2017) How digital tools and behavioral economics will save retirement. Available at: https://hbr.org/2017/12/howdigital-tools-and-behavioral-economicswill-save-retirement.

32. Hoyer WD, MacInnis DJ, Pieters R (2018) Consumer behavior, 7th edn. Cengage Learning, Boston, MA
33. Bulbul C, Menon G (2010) The power of emotional appeals in advertising. J Advert Res 50(2):169-180

34. Johnson EJ, Shu SB, Dellaert BG, Fox C, Goldstein DG, Häubl G, Weber EU (2012) Beyond nudges: tools of a choice architecture. Mark Lett 23(2):487-504

35. Islam MN, Bouwman, (2016) Towards user-intuitive web interface sign design and evaluation. Int J Hum Comput Stud. https:// doi.org/10.1016/j.ijhes.2015.10.003

36. Dolan P, Kudrna L, Laffan K (2016) Doing as I intend to: the role of 'implementation intentions' in financial behaviours London School of Economics and Political Science January 2016 Paul Dolan - Doing as I intend to do: the role of 'implementation intentions' in financial behaviours accessed on 12 May 2021

37. Balaraman V, Patel S, Duggirala M, Raveendran J, Mahamuni R (2020) People and the digital enterprise: challenges and approaches. In: Kulkarni V et al (ed) advanced digital architectures for model-driven adaptive enterprises, IGI Global, 188-221. DOI: https://doi.org/10.4018/978-1-7998-0108-5

38. Adiga D, Bhavsar M, Balaraman V, Duggirala M, Malik M (2019) Evolving a repository for the behavioral sciences, academy of management academy of management annual meeting proceedings, https://doi.org/10.5465/AMBPP.2019.18722 abstract

39. https://www.worldbank.org/en/topic/financialinclusion/overview accessed on 12 May 2021

40. https://www.worldbank.org/en/topic/financialinclusion/publication/ digital-financial-inclusion https://www.worldbank.org/en/topic/ financialinclusion/publication/digital-financial-inclusion accessed on 12 May 2021

41. https://www.bis.org/about/bisih/topics/open_finance.htm accessed on 12 May 2021

42. India digital financial inclusion report (2019) https://www.fhi360. org/sites/default/files/media/documents/resource-mstar-india-digi tal-financial-inclusion-report.pdf accessed on 12 May 2021

43. Datta S, Desai M (2018) Transforming financial inclusion using behavioral science from financial access to financial health, https://www.ideas42.org/wp-content/uploads/2019/04/I42-1020_ ABPaper_FINAL-DIGITAL.pdf accessed on 18 May 2021

44. OECD (2020) Advancing the digital financial inclusion of Youth https://www.oecd.org/finance/advancing-the-digital-financialinclusion-of-youth.pdf accessed on 12 May 2021 